\section{Special Issue: Driving and community mobility (II) - interventions to enable driving}

\author{
Carolyn A Unsworth ${ }^{1}$ and Priscilla A Harries ${ }^{2}$
}

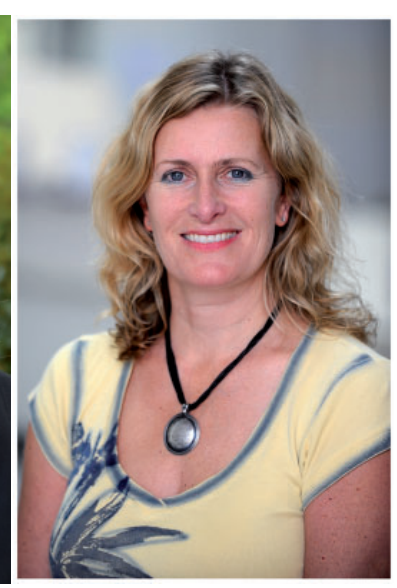

The first part of our Special Issue on 'Driving and community mobility' (British Journal of Occupational Therapy $78(2)$ ) focused on the assessment of drivers with health or age-related declines, and revealed over 25 years of research evidence that occupational therapists can use to help determine an individual's fitness-to-drive. The focus of this second part of our Special Issue is on occupational therapy interventions that support access to the community.

What happens when an individual's driving skills are impaired due to either congenital or acquired disabilities or the health declines associated with normal ageing? Being mobile around our community enables us to access services and link with friends, family and supports, thereby promoting community participation. Using either public or private transport, catching the bus or driving a car, is a vital occupation as well as being an occupational enabler. However, many clients are neither able to access transport nor to commence, resume or cease driving without some form of intervention. This issue opens with a paper examining occupational therapists' knowledge and attitudes toward giving advice on fitness-to-drive (Hawley, 2015) that found occupational therapists to have greater awareness and knowledge of United Kingdom (UK) guidelines on the medical standards of fitness-to-drive than psychologists and other health professionals. They suggest occupational therapists are well placed to expand their role in this practice area. A systematic review (Frith et al., 2015) of literature on return to driving following stroke and adherence to the guidelines on the medical standards also examined the extent to which stroke survivors routinely received education in the acute setting.
British Journal of Occupational Therapy 2015, Vol. 78(6) 337-338 (C) The Author(s) 2015 Reprints and permissions: sagepub.co.uk/journalsPermissions.nav DOI: $10.1177 / 0308022614566859$ bjo.sagepub.com

(SSAGE

Two papers focus on supporting clients who have mental health conditions to drive: McNamara et al. (2015) examined the lived experience of drivers who have bipolar disorder, while Dun and colleagues (2015) reported on the Drive Safe initiative implemented in their mental health service to monitor and support client driving.

Many driving clinics include the use of simulators to re/ train driving skills. A randomized controlled trial (Mazer et al. 2015) did not support the use of simulator training for clients in general with neurological impairments, suggesting instead that clients with moderate impairment may benefit. The advantages of clients being able to test and practise using vehicle modifications on a simulator prior to using these on the road are documented by Naveh et al. (2015). Although many individuals with health conditions can learn to drive, resume driving after an acquired incident, or maintain their driving despite age-related health declines, the complex skill level required to control a vehicle safely and independently is not always attained. The final papers examine occupational therapy interventions to support driving cessation, with one (Liddle et al., 2015) describing the experiences of peer leaders who run educational support groups for older people undergoing driving cessation, and another (Chan et al., 2015) reporting on how a driver retirement programme can support older taxi drivers' transition from their worker and driver roles.

The papers in this second part of our two-part Special Issue on 'Driving and community mobility' focus on interventions and achieve several aims: they document occupational therapists' expertise in this practice area; highlight the need to embed driving and community mobility issues in routine practice; and call for further training to enhance occupational therapists' knowledge in the domain.

${ }^{1}$ Professor of Occupational Therapy, Central Queensland University, Australia

${ }^{2}$ Head of Department for Clinical Sciences, Department for Clinical Sciences, Brunel University, UK

Corresponding authors:

Carolyn A Unsworth, Professor of Occupational Therapy, Central Queensland University, Melbourne Campus, 120 Spencer St, Melbourne, Vic 3000, Australia.

Email: c.unsworth@cqu.edu.au

Priscilla A Harries, Head of Department for Clinical Sciences, Mary Seacole Building, Brunel University London, Uxbridge UB8 3PH, UK.

Email: priscilla.harries@brunel.ac.uk 


\section{References}

Chan ML, Gustafsson L and Liddle J (2015) An intervention to support professional driver retirement transition: Results of a pilot study for older taxi drivers in Singapore. British Journal of Occupational Therapy 78(6): 391-400.

Dun C, Baker K, Swan J, et al. (2015) Drive Safe Initiatives: An analysis of improvements in mental health practices (20052013) to support safe driving. British Journal of Occupational Therapy 78(6): 364-368.

Frith J, Hubbard IJ, James CL, et al. (2015) Returning to driving after stroke: A systematic review of adherence to guidelines and legislation. British Journal of Occupational Therapy 78(6): 349-355.

Hawley C (2015) Knowledge and attitudes of occupational therapists to giving advice on fitness to drive. British Journal of Occupational Therapy 78(6): 339-348.
Liddle J, Liu Z, Aplin T, et al. (2015) The experiences of peer leaders in a driving cessation programme. British Journal of Occupational Therapy 78(6): 383-390.

Mazer M, Gélinas I, Duquette J, et al. (2015) A randomized clinical trial to determine effectiveness of driving simulator retraining on the driving performance of clients with neurological impairment. British Journal of Occupational Therapy 78(6): 369-376

McNamara and Buckley SE (2015) The road to recovery: Experiences of driving with bipolar disorder. British Journal of Occupational Therapy 78(6): 356-363.

Naveh Y, Shapira A and Ratzon NZ (2015) Using a driving simulator during vehicle adaptation. British Journal of Occupational Therapy 78: 377-382. 